University of Nebraska - Lincoln

DigitalCommons@University of Nebraska - Lincoln

Faculty Publications, UNL Libraries

Libraries at University of Nebraska-Lincoln

July 2002

\title{
Asterion and Chara - the Confusion of the Chase
}

Charles D. Bernholz

University of Nebraska-Lincoln, cbernholz2@unl.edu

Michael J. Lyons

Follow this and additional works at: https://digitalcommons.unl.edu/libraryscience

Part of the Library and Information Science Commons

Bernholz, Charles D. and Lyons, Michael J., "Asterion and Chara - the Confusion of the Chase" (2002). Faculty Publications, UNL Libraries. 7.

https://digitalcommons.unl.edu/libraryscience/7

This Article is brought to you for free and open access by the Libraries at University of Nebraska-Lincoln at DigitalCommons@University of Nebraska - Lincoln. It has been accepted for inclusion in Faculty Publications, UNL Libraries by an authorized administrator of DigitalCommons@University of Nebraska - Lincoln. 


\title{
Asterion and Chara-the confusion of the chase
}

\author{
Charles D Bernholz ${ }^{1}$ and Michael J Lyons ${ }^{2}$ \\ ${ }^{1}$ Memorial Library, State University of New York College at Cortland, Cortland, NY 13045, \\ USA \\ ${ }^{2}$ Port Jervis High School, Port Jervis, NY 12771, USA \\ E-mail: charlesb@em.cortland.edu
}

\begin{abstract}
The study of astronomy, as an important part of any science education programme, provides our students with insights into more than just the cosmos. It may also serve as a mechanism to link them to other natural and social sciences. This article examines equally valid interpretations of the constellation Canes Venatici as an example of how the study of astronomy may serve this multidisciplinary educational role. In addition, it is an extension of the thoughts of Stannard (2001) on communicating physics through story.
\end{abstract}

\begin{abstract}
"Astronomers and poets are blood brothers. The beauty of life which surrounds us is to be found not only in the laws governing the firmament but also in the laws of poetry."

Canes Venatici (Paustovsky 1970, p 207)
\end{abstract}

The evolution of scientific thought and knowledge has occurred, according to Popper (1972, pp 346-7), because “today's science is built upon yesterday's science; and yesterday's science in turn is based on the science of the day before. And the oldest scientific theories are built on prescientific myths, and these, in their turn, on still older expectations." As part of his presentation, Popper alludes to the tales or stories that dealt with "the beginnings of things, and which [tried] to understand or explain the structure of the Universe in terms of the story of its origin" (p 347). Such stories provided a society with the groundwork or a frame with which to maintain tradition and to provide answers to significant questions. The Greeks revered their gods through myths and stories of their endeavours and achievements, and through supplementing these tales with images cast in the overhead stars that conveyed the feats of these deities. Other cultures created, from their own observations, stories about the heavens. ${ }^{1}$ The drama of Perseus, Andromeda and the sea monster Cetus; the balance between Orion and Scorpius; the array of celestial animals: these familiar constellations formed the beginning of the union of storytelling and astronomy.

Today, astronomy is an important part of any science education program. One of its strengths as a discipline is that it reveals more than just the universe to our students. It can also serve as a mechanism to link pupils to other areas of instruction: to the worlds of history, geography and the social sciences. As the "oldest science" (Reed 1986, p 62), astronomy serves as a very useful platform to examine aspects of physics, and other fields of the sciences.

In a recent comment on physics education, Stannard (2001, p 30) queried: "Why should we

1 North America's indigenous peoples are a rich source of stories in the stars. See, for example, Mayo (1987). 
not use the art of storytelling to pass on our modern scientific wisdom?" Professor Stannard has written a good deal on the use of story to convey the ideas of physics to a larger audience. His series of Uncle Albert stories is a demonstration of his particular focus on successful ways to expose children to scientific principles. Indeed, his pursuit of an educational environment in which to support "flexible thinking" (p 32) by incipient science students relies on the interaction of the developing fascination of the students with the teaching skills of their instructor. The fruits of this approach will be maximized when students construct ideas from their own, or imagined, experiences (p 33)

In his description of his publications that offer a storytelling approach to the study of physics, Stannard revealed his own inspiration for presenting this content in this manner. It was material - C S Lewis's Screwtape Letterswhich conveyed a moral. He concluded "what is good for the teaching of morals is likely also to work when it comes to teaching physics" (p 34). A moral basis may also be seen in the history of the constellations, particularly revealed through Allen's (1963) multicultural vignettes of the interesting history of the star names. In that presentation, Allen described in detail the traditional constellation figures, but he also noted other alternative figures that were offered for these celestial forms. In the 16th century, Giordano Bruno proposed moral virtues such as Law and Truth as replacements. Julius Schiller exchanged, in the early 17th century, images of the Apostles for the twelve constellations of the zodiac (p 28). These descriptive approaches served as additional venues for using story to disclose important social data. Conveying important cultural content was one of the objectives that many Mediterranean societies achieved through their stories based on the stars.

Educators have used the study of constellations in the classroom to illustrate ways to encourage students to investigate the heavens in this creative manner (McLure 1984, Selin 1993a, 1993b, Lebofsky and Lebofsky 1996, Kalchman 1998). Staal's (1988) collection of myths and legends among the stars also reveals diverse interpretations of constellations. His compilation is an excellent reference resource for the constellations, and it is a trove of supporting materials for a storytelling approach to descriptions of the stars. Together, these materials demonstrate the evolution, over the millennia, of inventive thought to describe the heavens.

This article, through an examination of a less well-known constellation, Canes Venatici, accumulates various views of the ways that that universe has been perceived. It is the variety and the richness over time of these perceptionseven through the eyes of only western European observers in this example-that elevate the value of the study of astronomy in a science education program.

Canes Venatici is the constellation of the hunting dogs of Boötes (figure 1). ${ }^{2}$ These two Spring figures are in a never-ending pursuit of the Great Bear, Ursa Major. ${ }^{3}$ Indeed, Boötes, among other appellations, has been called the Hunter of the Bear (Allen 1963, p 93). The hunter and his quarry are very old yet clear constellations, but the dogs_-greyhounds to be specific-are a new addition to the night sky, composed of "a sprinkling of faint stars below Ursa Major" (Ridpath 1985, p 92). In 1690, Hevelius' new celestial atlas was published, ${ }^{4}$ and thereby introduced these participants into the chase around the Pole. ${ }^{5}$ Five Messier objects ${ }^{6}$ are within the modern boundaries of this constellation (figure 2$),{ }^{7}$ but there are only two prominent stars here. One, a double blue-white ( $\alpha \mathrm{CVn}$ ) named Cor Caroli or Charles' Heart after King Charles I, is the brightest at magnitudes 2.9 and 5.5, while $\beta \mathrm{CVn}$ is a magnitude 4.3 yellow star.

However, this is supposed to be a chase scene. Where are those dogs?

2 Figures 1 and 3 are from The Glorious Constellations: History and Mythology by Giuseppe Maria Sesti (C)1991. Published by Harry N Abrams, Inc., New York. Used with permission. All rights reserved. I thank David Savage at Harry $\mathrm{N}$ Abrams for this reprint permission.

3 See Allen (1963, pp 114-7, 92-106 and 419-47) for Canes Venatici, Boötes and the Great Bear, respectively.

4 Sesti (1991, p 89) acknowledged that "this is the most accurate catalogue in the history of stellar observation before the advent of the telescope."

5 The canines are missing from the famous, 1515 Albrecht Dürer plate of the Northern Hemisphere (Sesti 1991, p 92).

6 The five Messier objects are M3, M51, M63, M94 and M106 (Pasachoff 2000, pp 256-7).

7 Figure 2 is from A Field Guide to the Stars and Planets (4th edn) by Jay M Pasachoff @2000. Published by Houghton Mifflin Co., New York. Used with permission. All rights reserved. I thank Ronald Hussey at Houghton Mifflin for this reprint permission. 


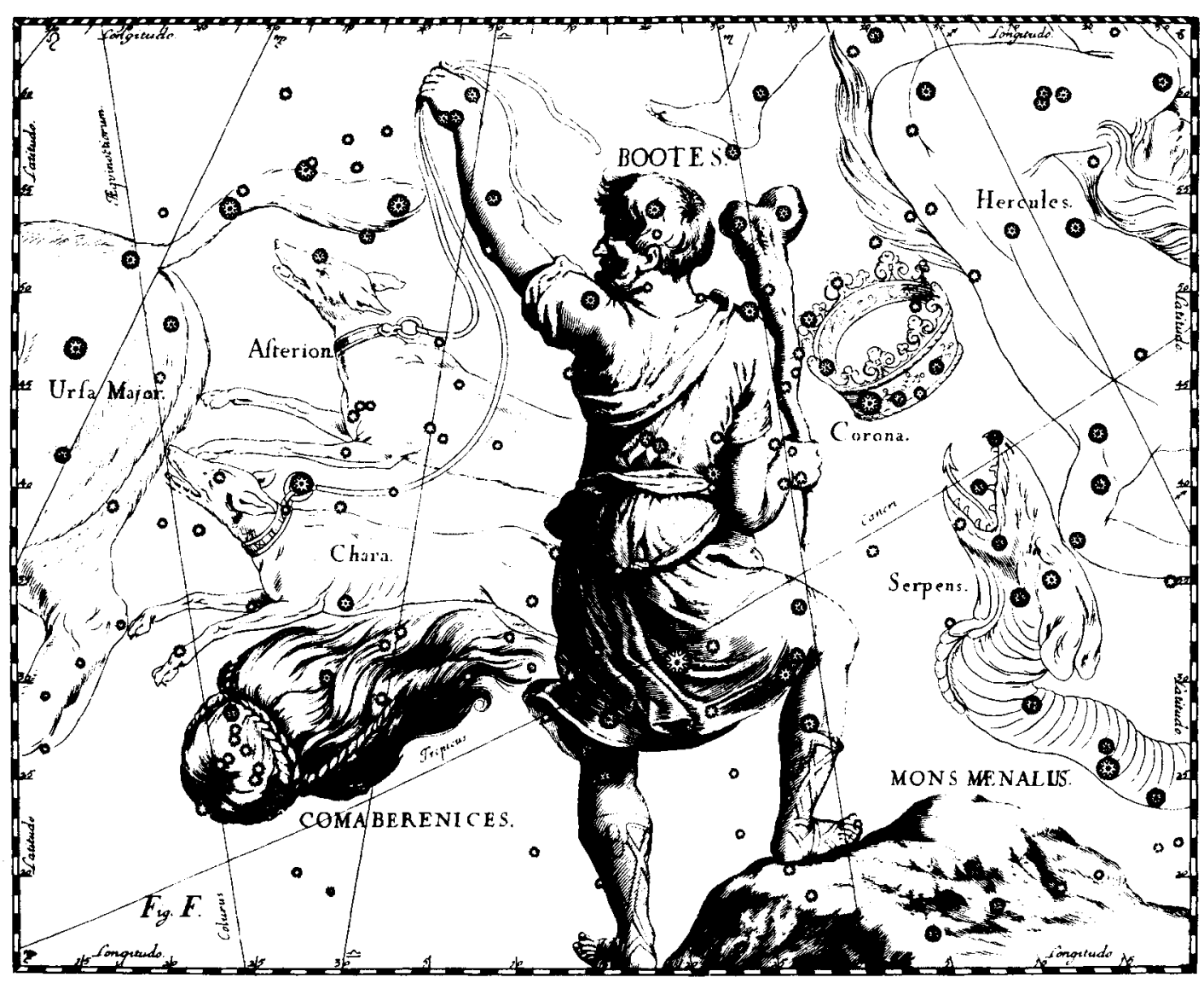

Figure 1. The constellation of Boötes, from Hevelius' 1690 Uranographia totum coelum stellatum (Sesti 1991, p 260). Note the names and the positions of the two greyhounds that compose the constellation Canes Venatici. Figures 1 and 3 are presented as if the constellations were on a celestial globe, with the observer farther out in space looking down onto this astral surface, while figures 2 and 4 are views of a normal, terrestrial observer.

We can see them quite clearly if we examine a copy of Hevelius' atlas (Volkoff 1971), ${ }^{8}$ but it is easier these days to see his proposed relationship between these dogs and the Great Bear in Sesti's (1991) The Glorious Constellations. ${ }^{9}$ In figure 3, we see the dogs nipping at the Bear. It is evident from this image that they are running hard, and we certainly know that the chase has gone on for many centuries. We can also note the names

8 The constellation chart of the northern hemisphere for Hevelius' Firmamentum Sobiescianum has images and names of these two canines, while the frontispiece of the same atlas has, in the lower left corner, images of these two during their mythological presentation by Hevelius to Urania, the Muse of Astronomy.

9 Sesti (1991, pp 260-5). This is the entry for Boötes, because Sesti's book only "presents forty-eight ancient constellations and the Milky Way" (p 23). There is no individual entry for the 'modern' constellation, Canes Venatici. Ursa Major is presented on pp 460-71. that Hevelius gave to the greyhounds. ${ }^{10}$ In these illustrations, Asterion is the more northern dog, while Chara runs along a lower, or more southern, route. Nevertheless, over the years, it seems that the dogs have run so hard and so long that-in the confusion-observers have seen them change positions in the sky. Sometimes Asterion is in the lead, occasionally Chara. At some point Asterion is the northern dog, but now and then Chara is the upper one. We know that the constellations appear to move across the sky, but do they appear to move that much?

We may examine well-known sources to see this variance. The scene of these dogs on the Summer page from Middleton's Celestial Atlas of 1843 has Asterion far to the north of Chara (Sesti

${ }^{10}$ An identical, though smaller, version of the same celestial map may be found on $p 127$ of Pasachoff (2000). 


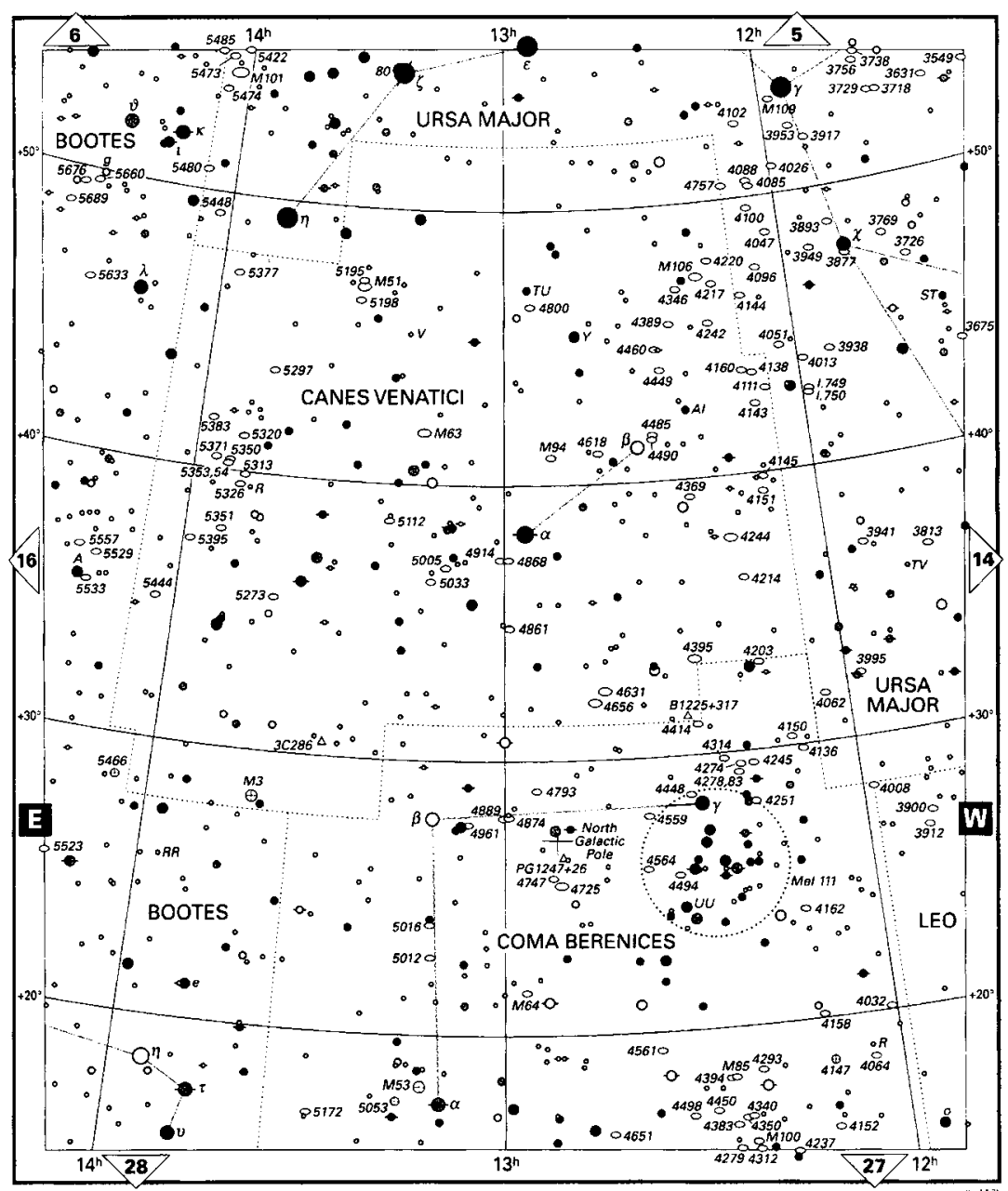

Figure 2. A modern celestial chart of the constellation Canes Venatici (Pasachoff 2000, p 257).

1991, p 115). Barry (1948, p 147) reported that " $[\mathrm{t}]$ he more northern dog is Asterion, marked by very faint stars. Chara, the other dog, contains Cor Caroli in its collar, and a 4th-magnitude star marked Beta, and also called Chara."11 Olcott's Field Book of the Skies (1954, p 108) noted that "Cor Caroli is located in Chara, the southern of the two hounds." Beyer (1986, p 119) indicated that "Cor Caroli and the fourth-magnitude star Chara mark the location of the Southern Hound, which is also known as Chara. The Northern Hound of Canes Venatici is called Asterion." Kunitzsch and Smart (1986) concurred with this, and additionally

${ }^{11}$ Lockwood's earlier article (1945, p 6) presented only Chara's composition as "Cor Caroli as well as Chara, which is the name sometimes used for the second brightest star, designated as Beta in the constellation." reported the specific stars from which Asterion is composed..$^{12}$ All these determinations are in conformity with the scene from Hevelius' atlas.

But just a moment. Ridpath (1985, pp 92-3) identified $\beta \mathrm{CVn}$ as "Asterion or Chara," although his celestial map has the name Asterion next to $\beta \mathrm{CVn}$. Klepešta and Rükl (1969) presented $\beta \mathrm{CVn}$ as Asterion in both their text and their map pages for Canes Venatici. Burnham (1978,

12 Their entry for $\beta \mathrm{CVn}$ has an error. The context clearly suggests that Asterion should be the 'northern,' and not the 'southern' dog. The stars' Flamsteed numbers-18, 19, 20 and $23 \mathrm{CVn}$-listed by the authors corroborate this. All lie north of $\alpha \mathrm{CVn}$. Three of the stars (19,20 and 23 CVn) form a straight line that is parallel to one between $\alpha$ and $\beta \mathrm{CVn}$, and these can be seen below M63 in Karkoschka (1990, p 39). This comparison, with all four stars identified by Flamsteed number, is evident on map 7 in Tirion (1981). 


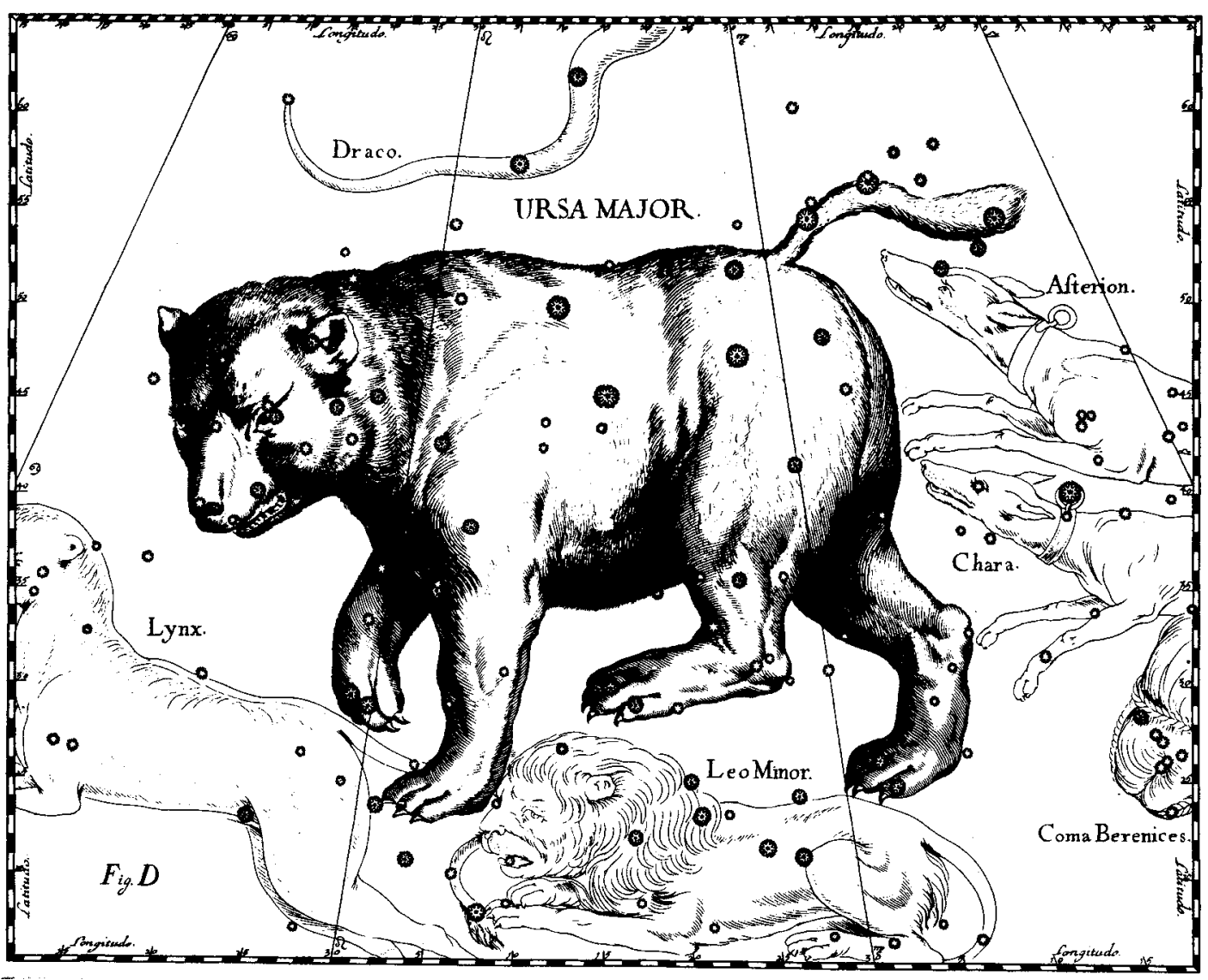

Figure 3. The constellation of Ursa Major, from Hevelius' 1690 Uranographia totum coelum stellatum (Sesti 1991, p 460).

p 359) declared that "Alpha Canum also marks the position of 'Chara,' one of the two hunting dogs in the mythological outline of the constellation. The other dog is named 'Asterion' and is marked by Beta." Staal (1988), in a figure that is attributed to the first Astronomer Royal, John Flamsteed, showed Asterion as the southern animal, composed of both $\alpha$ and $\beta \mathrm{CVn}$ (figure 4). ${ }^{13}$ Chara, with the Whirlpool Galaxy or M51 attached like a dog tag to its collar, was placed far to the north of Asterion. On the following page of Staal's book, two unidentified dogs are shown, the northern one marked by $\beta \mathrm{CVn}$, and the lower by $\alpha \mathrm{CVn}$. Similarly, the Audubon Society Field Guide to the Night Sky (Chartrand 1991,

\footnotetext{
${ }^{13}$ Figure 4 is from The New Patterns in the Sky: Myths and Legends of the Stars by Julius D W Staal @1988. Published by McDonald and Woodward Publishing Co., Blacksburg, Virginia. Used with permission. All rights reserved. I thank Dr Jerry McDonald for this reprint permission.
}

pp 456-7) stated that " $\alpha$, the more southerly of the constellation's two 'hounds' and the brightest star of Canes Venatici, is known as Cor Caroli," and that "Hevelius originally called it Asterion, 'starry one'." Further, the Guide declared that " $\beta$, the northerly 'hound,' is known as Chara, 'beloved'." This description is shown in the figure of the dogs in Eicher (1988). In a reversed image similar to the Boötes illustration in The Glorious Constellations, we see the greyhounds at full pursuit. However, if $\alpha \mathrm{CVn}$ was originally called Asterion, as the Audubon Society Field Guide to the Night Sky suggests, then the image of the lower or southern dog-on whose throat $\alpha \mathrm{CVn}$ is indicated in Eicher's illustration-must logically be that of Asterion. The $\beta \mathrm{CVn}$ star, Chara, is clearly on the neck of the northern dog and hence this must be the hunting dog of the same name. The Glorious Constellations images (figures 1 and 3) with which we began, though, have the names written next to 


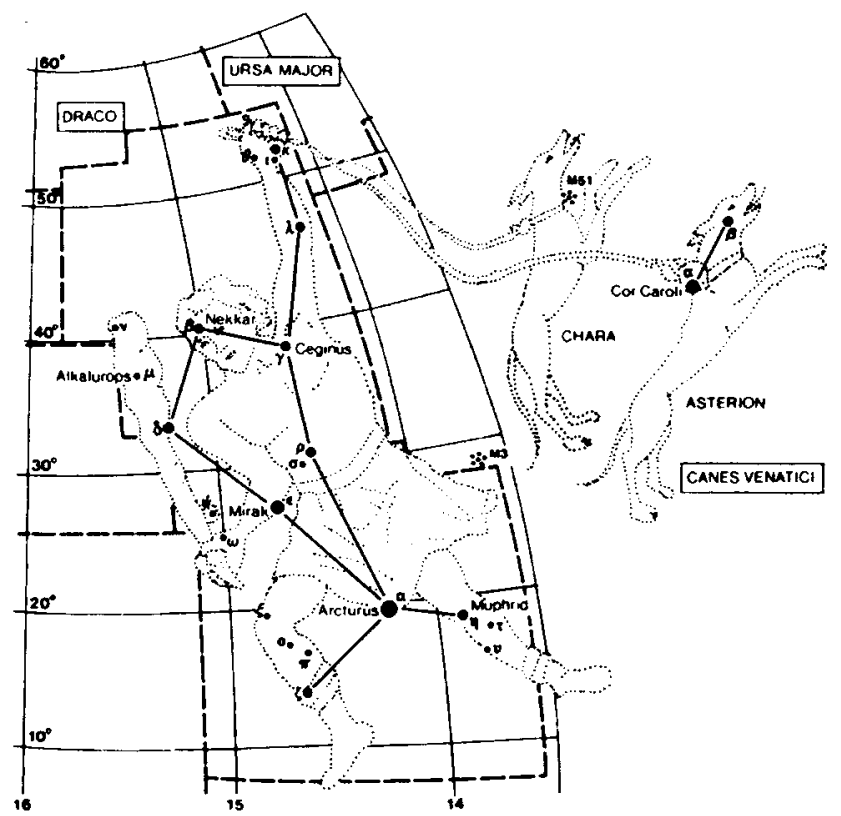

Figure 4. The constellations of Boötes and Canes Venatici, from Flamsteed's Atlas coelestis, 1729 (Staal 1988, $\mathrm{p}$ 153). Note the names and the positions of the two dogs, in comparison to those in figure 1.

the heads of these canines, and it is evident that the hounds are, respectively from the north, Asterion and Chara.

These differences offer a storyline for an application of Stannard's lesson proposals to a study of constellations. We may conclude that, during the constant chase around the Pole, the two greyhounds have strained for the lead in their quest for the Great Bear. The speed and the fury of the hunt, along with the keen eye of celestial observers, have produced dissimilar snapshots of this pursuit. We-as fortunate later students of their atlases and descriptions - are now treated to reports of first Asterion, then Chara, racing to the forefront or to the foreground in their rush for Ursa Major. Undoubtedly, we have from this one small example abundant material with which to teach physics.

As a supplement, the variability of these reports further divulges the importance of the perceptions of different observers. Allchin (2000, p 33) has suggested that "in encountering science historically, we should listen carefully so that we hear what history-and other scientists-try to tell us." These equivalent insights substantiate the desire to include the study of astronomy, and particularly of constellations, as an educational mechanism for enriching the learning experiences of our science students. It is certainly a captivating way to engage our pupils in the study of the "oldest science." Nevertheless, its application to Stannard's educational proposals is quite lucid. Examining the stars through stories and tales can develop wonder in our science students. This wonder can yield in turn the "flexible thinking" that will expand our opportunities to teach physics to these students in a productive manner.

Received 2 January 2002, in final form 2 May 2002 PII: S0031-9120(02)32183-X

\section{References}

Allchin D 2000 How not to teach historical cases in science J. Coll. Sci. Teaching 30 (1) 33-7

Allen R H 1963 Star Names: Their Lore and Meaning (New York: Dover)

Barry C E 1948 Spring skies Sky and Telescope 7 (6) 147

Beyer S L 1986 The Star Guide: a Unique System for Identifying the Brightest Stars in the Night Sky (Boston: Little, Brown)

Burnham R 1978 Burnham's Celestial Handbook: an Observer's Guide to the Universe Beyond the Solar System, vol. 1-Andromeda through Cetus (New York: Dover)

Chartrand M R 1991 The Audubon Society Field Guide to the Night Sky (New York: Knopf) 
Eicher E J 1988 The Universe from Your Backyard: a Guide to Deep-Sky Objects from Astronomy Magazine (Waukesha, WI: Kalmbach)

Kalchman M 1998 Storytelling and astronomy Sci. Children 36 (3) 28-31, 70

Karkoschka E 1990 The Observer's Sky Atlas: with 50 Star Charts Covering the Entire Sky (New York: Springer)

Klepešta J and Rükl A 1969 Constellations: a Concise Guide in Colour (London: Paul Hamlyn)

Kunitzsch P and Smart T 1986 Short Guide to Modern Star Names and Their Derivations (Wiesbaden: Otto Harrassowitz)

Lebofsky N R and Lebofsky L A 1996 Celestial storytelling Sci. Scope 20 (3) 18-21

Lockwood M 1945 The stars of Spring Sky and Telescope 4 (6) 6

Mayo G W 1987 Star Tales: North American Indian Stories about the Stars (New York: Walker)

McLure J W 1984 Polaris, Mark Kummerfeldt's star, and my star Sci. Teacher 51 (5) 80-2

Olcott W T 1954 Field Book of the Skies 4th edn (New York: Putnam)

Pasachoff J M 2000 A Field Guide to the Stars and Planets 4th edn (New York: Houghton Mifflin)

Paustovsky K 1970 Canes Venatici Selected Stories (Moscow: Progress)
Popper K R 1972 Objective Knowledge: An Evolutionary Approach (Oxford: Clarendon)

Reed G 1986 Ancient astronomers along the Nile Sci. Teacher 53 (6) 59-62

Ridpath I 1985 Universe Guide to Stars and Planets (New York: Universe)

Selin H 1993a Science across cultures. Part I: African and Native American achievements Sci. Teacher 60 (3) 38-44

Selin H 1993b Science across cultures. Part II: Chinese and Islamic achievements Sci. Teacher 60 (4) 32-6

Sesti G M 1991 The Glorious Constellations: History and Mythology (New York: Abrams)

Staal J D W 1988 The New Patterns in the Sky: Myths and Legends of the Stars (Blacksburg, VA: McDonald and Woodward)

Stannard R 2001 Communicating physics through story Phys. Educ. 36 (1) 30-4

Tirion W 1981 Sky Atlas 2000.0 (Cambridge, MA: Sky)

Volkoff I 1971 Johannes Hevelius and His Catalog of Stars (Provo, UT: Brigham Young University Press)

Charles D Bernholz is the Collections Librarian at the State University of New York College at Cortland.

Michael J Lyons is a student at Port Jervis, NY High School. 